\title{
REPRESENTAÇÃO INFORMACIONAL DE DOCUMENTOS ARTÍSTICOS EM AMBIENTE MUSEOLÓGICO: UMA ANÁLISE EXPLORATÓRIA SOB O PONTO DE VISTA DA INTEGRAÇÃO DEPARTAMENTAL
}

\author{
REPRESENTACIÓN INFORMACIONAL DE \\ DOCUMENTOS ARTÍSTICOS EN AMBIENTE \\ MUSEOLÓGICO: UN ANÁLISIS EXPLORATORIO DESDE \\ EL PUNTO DE VISTA DE LA INTEGRACIÓN \\ DEPARTAMENTAL
}

Giovana Deliberali Maimone ${ }^{a}$

\begin{abstract}
Resumo
Introdução: Analisa a integração dos departamentos museu, arquivo e biblioteca em ambiente museológico, no que diz respeito à representação informacional dos objetos/documentos artísticos, sendo que foram considerados todos os materiais referentes às artes, independentemente de seu suporte. Objetivos: Identificar a integração dos profissionais e dos acervos dos departamentos de museus em relação ao tratamento documentário dos diferentes tipos de materiais; contextualizar usos e ambiências destes documentos procurando delimitar fronteiras de aplicação documentária; e, comparar linguagens documentárias e ferramentas afins já existentes na área de artes. Metodologia: Foram realizados levantamentos e análises bibliográficas sobre o tema em questão, tendo como parte aplicada o envio e retorno de questionários à instituições de arte da cidade de São Paulo. Resultados: Muito embora existam diferenças entre os objetivos dos museus, esta pesquisa revelou a existência de iniciativas de integração tanto dos acervos quanto dos profissionais envolvidos com o trato informacional. Conclusões: É fundamental o trabalho integrado de representação de documentos artísticos sob o aspecto "informativo", uma vez que agregam valor ao conteúdo das obras.
\end{abstract}

Descritores: Representação da informação. Documentos artísticos. Museus. Arquivos. Bibliotecas.

\footnotetext{
${ }^{a}$ Doutora em Ciência da Informação pela Escola de Comunicações e Artes da Universidade de São Paulo. Professora da Universidade de São Paulo (USP). E-mail: gdmaimone@usp.br
} 


\section{INTRODUÇÃO}

O artigo que ora se apresenta é resultado de pesquisa realizada no departamento de Informação e Cultura (CBD) da Escola de Comunicações e Artes (ECA) da Universidade de São Paulo (USP) no período de 2014 a 2016 financiada pela Fundação de Amparo à Pesquisa do Estado de São Paulo (FAPESP) e cuja temática está vinculada à atuação docente da pesquisadora.

A representação informacional de documentos artísticos é analisada sob o ponto de vista da integração (acervos e profissionais) dos departamentos que compõem o museu (arquivo, biblioteca e o museu em si) desde suas atividades internas até o conhecimento dos objetivos e tarefas desempenhadas pelos outros dois departamentos.

Identificam-se diferenças e semelhanças entre os documentos presentes em cada acervo destes departamentos e seus modos específicos de tratá-los. Do ponto de vista informacional reconhece-se a coleção como ponto de partida para o tratamento temático e descritivo das obras, sendo que a ênfase dada à esta pesquisa recai sobre o primeiro (tratamento temático/representação de assuntos). Discorre-se, sob este prisma, sobre algumas das ferramentas utilizadas para classificar e indexar materiais de arte que podem ser utilizadas pelas bibliotecas e adaptadas para o uso em arquivos e museus.

Além desta introdução, conta-se com um capítulo teórico sobre o ambiente museológico e as linguagens controladas para representação de documentos artísticos, prosseguindo-se para a parte prática na qual é exposta a metodologia da pesquisa utilizada, os resultados alcançados (análises) e as conclusões a que se pôde chegar.

\section{AMBIENTE MUSEOLÓGICO}

Os departamentos do museu trabalham com tipos diferentes de materiais (características físicas e conteudísticas), fato que pressupõe usos diversificados. Por este motivo, as atividades de organização informacional de cada um deles são também variadas. O museu, em relação ao acervo 
expositivo, por exemplo, tem suas preocupações pautadas mais na contemplação das obras do que no conteúdo informacional que as mesmas podem trazer, sendo esta última o maior objetivo da biblioteca. O arquivo, como traz informação referencial e da trajetória das obras, serve de fonte para pesquisa histórica e trabalho interno de organização de exposições e/ou empréstimo de obras entre museus.

Embora existam tais diferenças, é importante ressaltar que, no contexto virtual, tais informações podem ser visualizadas de modo integrado e interagem para pesquisas mais completas dentro dos sistemas de informação. De todo modo, é fundamental ressaltar que as diferenças de acervos dos departamentos do museu refletem no modo de organização da informação já que estas se modificam de acordo com os critérios utilizados para tratá-las (SMIT, 1999-2000).

Neste sentido, de acordo com Desvallées e Mairesse (2013, p.89) é possível mencionar que existe uma "sociedade" para a qual os museus direcionam seus trabalhos, sendo

[...] uma comunidade de indivíduos, organizada (em um espaço e em um momento definidos) em torno de instituições políticas, econômicas, jurídicas e culturais comuns, entre as quais está o museu e com as quais ele constrói a sua atividade. (DESVALLÉES; MAIRESSE, 2013, p.89).

A coleção presente em cada museu influi diretamente em seu público e a constituição destes ambientes é pensada de modo a desconstruir uma noção para reconstruí-la, sendo que as obras perdem seu sentido original para fazerem parte de uma contextualização previamente planejada, sendo que os objetos se transformam em musealia. Enfatiza-se, portanto, que a coleção no ambiente museológico deve ser constituída por um conjunto de objetos, adequadamente reunidos e conservados para serem comunicados ao público, sendo que os mesmos devem formar um conjunto coerente e significativo (DESVALLÉES; MAIRESSE, 2013).

A partir da coleção é possível dizer que a Ciência da Informação integrase ao museu trabalhando sob a ótica do tratamento da informação, 
independentemente do tipo de material que reúne. Neste sentido, às obras devem ser atribuídos termos oriundos de linguagens controladas, que permitam maior gerenciamento das coleções, além de uma estrutura (padrão/sistema) para inserção dos dados/informações.

Durante muito tempo arquivo, museu e biblioteca (aqui trabalhados como departamentos integrados do ambiente museológico) eram tratados como locais de "depósitos" de documentos produzidos pelo homem, que compartilhavam então o objetivo da "guarda" dos materiais. É relevante, porém, esclarecer, na atualidade, suas diferenças a partir das definições.

- Arquivo - é a acumulação ordenada dos documentos, em sua maioria textuais, criados por uma instituição ou pessoa, no curso de sua atividade, e preservados para a consecução de seus objetivos, visando à utilidade que poderão oferecer no futuro.

- Biblioteca - é o conjunto de material, em sua maioria impresso, disposto ordenadamente para estudo, pesquisa e consulta.

- Museu - é uma instituição de interesse público, criada com a finalidade de conservar, estudar e colocar à disposição do público conjuntos de peças e objetos de valor cultural. (PAES, 2004, p. 16, grifos da autora).

Os documentos de arquivo podem ser organizados de acordo com forma e conteúdo; quanto ao gênero, os documentos podem ser:

escritos ou textuais: documentos manuscritos, datilografados ou impressos;

cartográficos: documentos em formatos e dimensões variáveis, contendo representações geográficas, arquitetônicas ou de engenharia (mapas, plantas, perfis);

iconográficos: documentos em suportes sintéticos, em papel emulsionado ou não, contendo imagens estáticas (fotografias, diapositivos, desenhos, gravuras);

filmográficos: documentos em películas cinematográficas e fitas magnéticas de imagem (tapes) conjugados ou não a trilhas sonoras, com bitolas e dimensões variáveis, contendo imagens em movimento (filmes e fitas videomagnéticas);

sonoros: documentos com dimensões e rotações variáveis, contendo registros fonográficos (discos e fitas audiomagnéticas);

micrográficos: documentos em suporte fílmico resultantes da microrreprodução de imagens, mediante utilização de técnicas 
específicas (rolo, microficha, jaqueta, cartão-janela);

informáticos: documentos produzidos, tratados ou armazenados em computador (disquete, disco rígido winchester -, disco óptico). (PAES, 2004, p.29, grifos da autora).

Em arquivos de Artes são mais comuns documentos iconográficos, filmográficos e informáticos já que podem acompanhar as obras presentes no espaço expositivo e até complementá-las como é o caso das fotografias, filmes e textos web. Já quanto à natureza do assunto, Paes (2004, p.29) identifica dois tipos de documentos: ostensivos e sigilosos.

\begin{abstract}
A classificação de ostensivo é dada aos documentos cuja divulgação não prejudica a administração. Consideram-se sigilosos os documentos que, por sua natureza, devam ser de conhecimento restrito e, portanto, requeiram medidas especiais de salvaguarda para sua custódia e divulgação. Pela sua importância, a matéria é objeto de legislação própria (PAES, 2004, p.29-30).
\end{abstract}

Documentos de natureza privada (como arquivos de família, fotos, correspondências de conteúdos não autorizados para divulgação e valores envolvidos para compra e venda de obras) devem ser armazenados com sigilo e atenção dos profissionais que cuidam de tal acervo. Outros documentos que não tenham restrições ao conteúdo podem permanecer de acesso público.

Nas bibliotecas dos museus, os materiais deveriam oferecer maior especificidade de tratamento documentário de conteúdo, uma vez que o público é também mais especializado. Porém, conforme constatado nos questionários respondidos (como se verá mais adiante), os documentos de nossas bibliotecas ainda carecem de tratamento mais especializado, embora existam iniciativas neste sentido, como é o caso do grupo de profissionais de arte que se reúnem para definir parâmetros comuns que norteiem o tratamento dos acervos da área de Artes (REDARTE).

\footnotetext{
${ }^{\mathrm{b}}$ É necessário explicitar que do grupo da REDARTE participam profissionais não somente de bibliotecas, mas de arquivos e museus também.
}

Inf. Inf., Londrina, v. 23, n. 01, p. $109-131$, jan./abr. 2018. http://www.uel.br/revistas/informacao/ 
Segundo o Comitê Internacional de Documentação (2014, p. 42) os museus possuem um tipo de tratamento informacional (documentação) especializado que envolve

[...] registros que documentam a criação, a história, a aquisição feita pelo museu e a história subsequente de todos os objetos do acervo. Esses registros incluem documentos de origem e procedência, documentos de aquisição, relatórios de conservação, fichas de catalogação, imagens e pesquisas criados tanto pela instituição detentora do objeto, como por proprietários anteriores, pesquisadores independentes, etc. $\mathrm{O}$ termo também se aplica ao processo de coleta dessas informações (COMITÊ INTERNACIONAL, 2014, p.42).

Dos grupos de informações apresentados pelo mesmo órgão é importante, para este trabalho, apresentarmos os seguintes:

Grupo de Informação de descrição (descrição física e situação do espécime ${ }^{c}$ );

Grupo de Informação de imagem (tipo de imagem e número de referência da imagem);

Grupo de Informação de material e técnica (material, técnica e descrição de parte ou componente);

Grupo de Informação de medição (dimensão, medição, unidade de medida, parte medida);

Grupo de Informação de catalogação (catalogador, data de catalogação e autoridade);

Grupo de Informação de assunto representado (assunto representado e descrição do assunto representado). (COMITÊ INTERNACIONAL, 2014, p.51, grifos nossos).

Exemplificando as descrições solicitadas pelos grupos de informações acima relacionados temos:

Descrição física: Armário marchetado com mogno, pau-rosa e outros tipos de madeira, painéis...

Tipo de imagem: digital / Número de referência da imagem: 765123.23

ou

Tipo de imagem: fotografia colorida / Número de referência da

\footnotetext{
${ }^{\mathrm{c}}$ Espécime $=$ objeto.
}

Inf. Inf., Londrina, v. 23, n. 01, p. $109-131$, jan./abr. 2018.

http://www.uel.br/revistas/informacao/ 
imagem: 1992-32

Material: algodão / Técnica: bordado / Parte ou componente do objeto: inteiro.

Dimensão: altura / Medida: 23 / Unidade de medida: $\mathrm{cm} /$ Parte medida: escultura, excluindo a base.

Catalogador: Legrand, M. / Data de registro: 23 - 04 - 1992 / Autoridade: Delahaye, F.

Assunto representado: paisagem marinha / Assunto representado: barcos à vela / Descrição do assunto representado: praia e mar próximos a uma cidade com barcos à vela e mar agitado ${ }^{d}$

ou

Assunto representado: Iconografia / Descrição do assunto representado: Em primeiro plano, mulher colhendo batatas em um campo com uma aldeia ao fundo da composição (COMITÊ INTERNACIONAL, 2014, p. 51).

Ainda sobre o tema da documentação em museus, a norma SPECTRUM 4.0 (2014) que rege a gestão de coleções de museus do Reino Unido traz uma série de procedimentos adotados como padrão, dentre eles: entrada do objeto, aquisição, controle de inventário, catalogação, gestão de riscos e auditoria, para citar alguns. Dentre estes o que nos interessa mais diretamente é o que se refere a catalogação, já que tal norma não inclui a representação temática. Assim, a catalogação deve contar com informações que permitam:

Fornecer um nível de descrição suficiente para identificar um objeto ou grupo de objetos e as suas diferenças de outros objetos semelhantes;

Fornecer um arquivo histórico relacionado ao objeto ou referências cruzadas para as fontes onde as informações podem ser encontradas;

Ser mantida num sistema que permita fácil acesso, por exemplo, com busca usando índices ou texto livre. (SPECTRUM, 2014, p.55).

O segundo item acima listado é o diferencial do sistema do Reino Unido, uma vez que demonstra preocupação com a pesquisa, oferecendo um arcabouço de informações e referências.

\footnotetext{
${ }^{d}$ Este grupo de informação poderá incluir informações sobre pessoas, lugares, eventos ou objetos representados.
}

Inf. Inf., Londrina, v. 23, n. 01, p. $109-131$, jan./abr. 2018. 
Os materiais de arte são tratados de maneiras diferentes no museu, no arquivo e na biblioteca, porém o elo que os liga está na informação que carregam e que se complementam permitindo maior amplitude de conhecimento sobre determinado assunto, artista, obra, entre outros. Há indicativos de uma crescente preocupação em integrar as informações destes ambientes, essencialmente pela introdução do ambiente virtual que possibilita, além de personalizar a base de acordo com as necessidades locais, também a troca informacional e o contato mais efêmero e efetivo dos profissionais envolvidos.

\subsection{REPRESENTAÇÃO DE DOCUMENTOS ARTÍSTICOS E LINGUAGENS CONTROLADAS}

A representação documentária conta com processos ligados à descrição física dos materiais, além de uma linha temática, que objetiva atribuir assunto aos mesmos. Ambos os processos contam com instrumentos que orientam sua operacionalização, sendo que nesta pesquisa trabalha-se especificamente com ferramentas que sistematizam a parte temática.

A pesquisa realizada através da análise das estruturas dos Sistemas de Classificação Decimal (de Dewey e Universal) em Artes, a definição de alguns conceitos pela norma ANSI / NISO Z39.19-2005', a padronização oferecida pela Norma ISO 25964', e os relacionamentos terminológicos do Art \& Architecture Thesaurus, juntamente com investigação de trabalhos do CIDOC $^{9}$ $\mathrm{ICOM}^{\mathrm{h}}$, fornecem base para validar as relações materiais (procedimentais) existentes dentro dos referidos departamentos.

A Classificação Decimal de Dewey (23a . edição, publicada em 2011') apresenta as Artes na classe 700, sendo que seus conteúdos estruturam-se do seguinte modo:

\footnotetext{
e Diretrizes para a construção, formato e gestão de vocabulários controlados monolíngues.

${ }^{\mathrm{f}}$ Thesauros e interoperabilidade com outros vocabulários.

${ }^{9}$ CIDOC - International Committee for Documentation.

${ }^{\mathrm{h}}$ ICOM - International Council of Museums.

'Acessada através do portal webdewey.
} 


\begin{tabular}{|l|l|}
\hline 700 Artes e recreação \\
\hline 700 & Artes \\
\hline 710 & Ordenamento do território e arquitetura da paisagem \\
\hline 720 & Arquitetura \\
\hline 730 & Escultura, cerâmica e metalurgia \\
\hline 740 & Artes gráficas e artes decorativas \\
\hline 750 & Pintura \\
\hline 760 & Gravura \& impressões \\
\hline 770 & Fotografia, arte de computador, filme e vídeo \\
\hline 780 & Música \\
\hline 790 & Esportes, jogos e entretenimentos \\
\hline
\end{tabular}

Já a estrutura da mesma classe na Classificação Decimal Universal (Referente ao Consórcio da UDC - Universal Decimal Classification, 3‥ edição, publicada em 2005 - Lisboa) especifica um pouco mais essas relações, sendo:

\begin{tabular}{|l|l|}
\hline \multicolumn{2}{|l|}{7 Arte. Recreação. Entretenimento. Desporto } \\
\hline 7 & Arte em geral. \\
\hline 71 & $\begin{array}{l}\text { Planeamento territorial, físico. Planeamento regional, urbano e } \\
\text { rural. Paisagens, parques, jardins. }\end{array}$ \\
\hline 72 & Arquitetura. \\
\hline 73 & Artes plásticas. \\
\hline 74 & Desenho. Design. Artes e ofícios aplicados. \\
\hline 75 & Pintura. \\
\hline 76 & Artes Gráficas. Gravura. \\
\hline
\end{tabular}

Inf. Inf., Londrina, v. 23, n. 01, p. $109-131$, jan./abr. 2018. 


\begin{tabular}{|l|l|}
\hline 77 & Fotografia e processos similares. \\
\hline 78 & Música. \\
\hline 79 & Divertimentos. Espetáculos. Jogos. Desportos. \\
\hline
\end{tabular}

Observa-se nitidamente que a preocupação destes sistemas é a organização física por semelhança dos materiais, fato que permite agrupar tanto livros como obras de arte num mesmo local, embora o espaço do museu, em muitos casos são escassos e/ou são escolhidos outros tipos de relações. Enfatiza-se que o assunto, nas Artes, é classificado como "tipo de" Arte e não como "de que tratam" as obras.

A norma ANSI/NISO Z39.19-2005 apresenta as "Diretrizes para a construção, formato e gestão de vocabulários controlados monolíngues" e explicita os propósitos destas ferramentas.

[...] o propósito dos vocabulários controlados é fornecer meios para organizar a informação. Através de processos de atribuição de termos selecionados dos vocabulários controlados para descrever documentos e outros tipos de conteúdos de objetos, materiais são organizados de acordo com vários elementos que foram escolhidos para descrevê-los. (AMERICAN NATIONAL STANDARDS ORGANIZATION, 2005, p.10).

Utiliza-se o vocabulário controlado para indexar os materiais de acordo com seu conteúdo, já que serve para cinco propósitos:

1 Tradução: proporcionar um meio para converter a linguagem natural dos autores, indexadores, e os utilizadores para um vocabulário que pode ser usado para indexação e recuperação.

2 Consistência: promover a uniformidade em formato e na atribuição de termos.

3 Indicação de relacionamentos: indicar relações semânticas entre termos.

4 Rotular e navegar: fornecer hierarquias consistentes e claras dentro de sistemas de navegação para ajudar os usuários a localizar conteúdos de objetos desejados.

5 Recuperação: servir como uma ajuda de busca para localizar conteúdos de objetos. (AMERICAN NATIONAL STANDARDS ORGANIZATION, 2005, p.10). 
Os vocabulários controlados, portanto, intentam organizar os materiais em termos de uma linguagem especializada, ou seja, a partir de uma área do conhecimento específica, como é o caso dos tesauros.

A norma ISO 25964 intitulada "Thesauros e interoperabilidade com outros vocabulários" subdivide-se em duas partes, sendo a primeira versando sobre os tesauros para recuperação da informação (2011) e a segunda trabalhando com a interoperabilidade destes com outros vocabulários (2012). Estas normas servem de base estrutural para entendimento dos tesauros, verificando os tipos de termos utilizados, seus conceitos e suas relações com outros termos a fim de compreender como estes são estruturados no interior da linguagem. Recorrendo aos estudos terminológicos, os tesauros se mostram importantes instrumentos de recuperação da informação, principalmente em sistemas informatizados.

Especificamente em termos de Artes, o Instituto Getty, lançou em 2010 o "Introduction to controlled vocabularies: terminology for art, architecture and other cultural Works", obra importante que confirma a função dos museus no sentido de sua abrangência: "satisfazer a uma ampla gama de usuários, de pesquisadores eruditos até visitantes novatos do Web site". (HARPRING, 2010, p.173). Para isso, "termos de indexação necessitarão ser específicos o suficiente para permitir que os registros permaneçam significativos no contexto maior do repositório de informação". (HARPRING, 2010, p.174).

Necessário enfatizar, porém, que, conforme visualizado na pesquisa de campo, o cenário analisado demonstra desempenho insuficiente na aplicação das linguagens documentárias, se observadas as especificidades do campo artístico. Sabe-se, por exemplo, que, dependendo do museu um assunto pode ser considerado como o nome de um artista, ou uma instituição museológica apenas, sem implicações temáticas.

\footnotetext{
${ }^{j}$ A partir de 2016 a obra ganhou edição nova e lançamento em português.
} 


\section{METODOLOGIA}

A metodologia da pesquisa é considerada exploratória descritiva, contando com levantamento e estudo bibliográfico, e a análise de um questionário previamente elaborado com o objetivo de traçar um panorama da integração de informações museológicas partindo-se do ponto de vista da representação informacional de documentos artísticos. Foi possível trabalhar com o retorno dos respondentes, mais especificamente quatro instituições ${ }^{k}$ da cidade de São Paulo' e trazer alguns resultados. O referido questionário encontra-se a seguir:

\section{QUESTIONÁRIO DE PESQUISA CIENTÍFICA}

\section{Processo FAPESP no:}

\section{Professora:}

\section{Objetivos do questionário}

Pretende-se, com este questionário, verificar a integração existente entre os diferentes departamentos, acervos e profissionais dos museus de arte da cidade de São Paulo.

Observação conceitual: São considerados como "documentos de arte", todos os materiais que expressem ou tenham relação direta ou indireta com as obras de arte. Exemplos: pintura, escultura, desenho, livro sobre arte, registro de entrada da obra em determinado acervo, nota fiscal de compra, etc.

\section{Dados Gerais}

Instituição:

Identificação do respondente:

\footnotetext{
${ }^{k}$ Todas as respondentes foram bibliotecas, fato que impossibilitou a visão completa da pesquisa inicialmente proposta. Porém, mesmo que parcial, o trabalho possibilitou visualizar a integração destes setores (bibliotecas) com os demais (arquivos e museus).

' Ficaram resguardados os direitos de anonimato das instituições respondentes, uma vez que esta pesquisa tem caráter estritamente acadêmico.
} 
Cargo ocupado na Instituição:

\section{Departamento ao qual o respondente pertence}

( ) Biblioteca

( ) Arquivo

( ) Museu (exposição)

1. Os documentos de arte são representados temática e descritivamente?

( ) SIM -> prossiga para a questão 2

( ) NÃO -> Justifique:

2. Descreva o modo como os documentos são representados.

3. Existe (m) algum (ns) instrumento específico utilizado para a representação temática e descritiva dos documentos de arte?

( ) SIM $\rightarrow$ Qual

(is)?

( ) NÃO -> Justifique:

4. Há um sistema informacional automatizado que integre as informações de cada departamento (biblioteca, arquivo e museu)? ( ) SIM -> Qual?

( ) NÃO -> Justifique:

5. Realiza-se trabalho cooperativo e/ou atividades conjuntas envolvendo os 03 departamentos? 
( ) SIM -> Como se

realizam?

( ) NÃO -> Justifique:

6. Seu departamento conhece a finalidade e as atividades realizadas pelos outros dois?

( ) SIM

( ) NÃO

7. Qual a finalidade do material processado informacionalmente no seu departamento? Liste e diferencie entre usuários internos e externos.

Objetivamente intentou-se conhecer as possibilidades e características de integração existentes em cada instituição/departamento e, de modo mais específico, transcreve-se abaixo o que se esperava de cada questão/resposta.

Questão 1 - Saber da preocupação de cada departamento em realizar a representação de documentos.

Questão 2 - Conhecer os procedimentos utilizados para tal representação.

Questão 3 - Conhecer os instrumentos utilizados para efetivar tais atividades.

Questão 4 - Saber se existe um sistema informacional integrado e, em caso positivo, se este por si só já envolve uma equipe interdisciplinar (perspectiva interessante e fundamental para a integração).

Questão 5 - O trabalho cooperativo e as atividades conjuntas que sinalizam interesses das Instituições nas trocas informacionais e de trabalho de cada departamento.

Questão 6 - O conhecimento e a possível "convivência" entre as equipes dos departamentos que podem implicar em reciprocidade/cooperação nas atividades realizadas. 
Questão 7 - Saber para que tipo de público os documentos são representados. Se existem segmentos específicos e se os sistemas são pensados para cada um deles.

\section{RESULTADOS}

Os resultados foram obtidos através de análises das respostas do questionário enviado, elencadas abaixo, após a tabela que as embasam:

\section{Tabela 1: Retorno dos questionários}

\begin{tabular}{|c|c|c|c|c|}
\hline & Instituição 1 & Instituição 2 & Instituição 3 & Instituição 4 \\
\hline $\begin{array}{l}\text { Questão 1 } \\
\text { Os Documentos de } \\
\text { Arte são } \\
\text { representados? }\end{array}$ & Sim & Sim & Sim. & Sim. \\
\hline $\begin{array}{l}\text { Questão } 2 \\
\text { Se sim, de que } \\
\text { modo é feita essa } \\
\text { representação? }\end{array}$ & $\begin{array}{l}\text { São } \\
\text { representados } \\
\text { pela indexação } \\
\text { padrão } \\
\text { (vocabulário } \\
\text { controlado) }\end{array}$ & Em branco & $\begin{array}{l}\text { Documentos } \\
\text { passam por } \\
\text { tratamento } \\
\text { técnico } \\
\text { descritivo, para } \\
\text { posterior } \\
\text { digitação na } \\
\text { planilha MARC } \\
\text { do sistema. Os } \\
\text { campos notas } \\
\text { são retirados da } \\
\text { OCLC, e se } \\
\text { necessário } \\
\text { acrescentamos } \\
\text { notas relativas a } \\
\text { esta biblioteca } \\
\text { em particular. }\end{array}$ & $\begin{array}{l}\text { O tratamento do } \\
\text { acervo é realizado } \\
\text { por um setor } \\
\text { específico de } \\
\text { Suporte Técnico. } \\
\text { Os catalogadores } \\
\text { realizam uma } \\
\text { análise conceitual } \\
\text { e temática do } \\
\text { material a partir } \\
\text { de uma leitura } \\
\text { técnica na qual se } \\
\text { extrai os termos } \\
\text { representativos do } \\
\text { documento e a } \\
\text { sua descrição, } \\
\text { levando em conta } \\
\text { o conteúdo da } \\
\text { obra, a demanda } \\
\text { dos nossos } \\
\text { leitores e a } \\
\text { natureza da } \\
\text { biblioteca. }\end{array}$ \\
\hline $\begin{array}{l}\text { Questão 3 } \\
\text { Utiliza-se algum } \\
\text { instrumento } \\
\text { específico para } \\
\text { representá-los? }\end{array}$ & $\begin{array}{lr}\text { Não. } & \mathrm{Na} \\
\text { Biblioteca, os } \\
\text { documentos de } \\
\text { arteraaro } \\
\text { essencialmente } \\
\text { livros sobre arte } \\
\text { e são indexados } \\
\text { e representados } \\
\text { como todos os } \\
\text { demais livros, } \\
\text { muitas vezes }\end{array}$ & $\begin{array}{l}\text { Sim. AACR2 } \\
\text { (Biblioteca). }\end{array}$ & $\begin{array}{l}\text { Sim. MAP } \\
\text { Mapping artists } \\
\text { publication. }\end{array}$ & $\begin{array}{l}\text { Não. Embora não } \\
\text { exista nenhum } \\
\text { instrumento } \\
\text { especializado } \\
\text { para a área de } \\
\text { arte, há um grupo } \\
\text { de profissionais } \\
\text { que se reúnem } \\
\text { periodicamente } \\
\text { para avaliar os } \\
\text { trabalhos e definir }\end{array}$ \\
\hline
\end{tabular}

Inf. Inf., Londrina, v. 23, n. 01, p. 109 - 131, jan./abr. 2018. http://www.uel.br/revistas/informacao/ 


\begin{tabular}{|c|c|c|c|c|}
\hline & $\begin{array}{l}\text { mais } \\
\text { detalhadamente, } \\
\text { já que possuem } \\
\text { características } \\
\text { próprias, mas } \\
\text { sempre } \\
\text { respeitando as } \\
\text { diretrizes de } \\
\text { catalogação } \\
\text { para Bibliotecas. }\end{array}$ & & & $\begin{array}{lr}\text { parâmetros } & \\
\text { comuns } & \text { que } \\
\text { norteiem } & \text { o } \\
\text { tratamento dos } \\
\text { acervos de artes. }\end{array}$ \\
\hline $\begin{array}{l}\text { Questão } 4 \\
\text { Existe um sistema } \\
\text { informacional que } \\
\text { integra o acervo } \\
\text { dos } \\
\text { departamentos } 03 \\
\text { arquivo, museu e } \\
\text { biblioteca? }\end{array}$ & $\begin{array}{l}\text { Sim. Sistema de } \\
\text { Gerenciamento } \\
\text { de Acervos - } \\
\text { SGA } \\
\text { (desenvolvido } \\
\text { pela própria } \\
\text { instituição) }\end{array}$ & $\begin{array}{ll}\text { Sim. ABCD } & - \\
\text { Para } & \text { a } \\
\text { Biblioteca } & \mathrm{e} \\
\text { para } & \mathrm{o} \\
\text { Arquivo. } & \end{array}$ & Não. & $\begin{array}{l}\text { Sim. Alexandria. } \\
\text { Os catálogos de } \\
\text { arte, porém, não } \\
\text { se encontram no } \\
\text { referido sistema. }\end{array}$ \\
\hline $\begin{array}{lr}\text { Questão } 5 & \\
\text { Existe trabalho } \\
\text { cooperativo ou } \\
\text { atividades } \\
\text { conjuntas? }\end{array}$ & $\begin{array}{l}\text { Sim. Realizam- } \\
\text { se em forma de } \\
\text { exposições, } \\
\text { visitas } \\
\text { monitoradas e } \\
\text { eventos, como } \\
\text { palestras re } \\
\text { seminários. }\end{array}$ & $\begin{array}{l}\text { Sim. Grupos } \\
\text { de trabalho } \\
\text { temáticos. }\end{array}$ & Em branco. & $\begin{array}{l}\text { Sim. Há uma base } \\
\text { de dados conjunta } \\
\text { dos acervos de } \\
\text { todos os } \\
\text { equipamentos do } \\
\text { Sistema Municipal } \\
\text { de Bibliotecas. }\end{array}$ \\
\hline $\begin{array}{lr}\text { Questão } 6 \\
\text { É de conhecimento } \\
\text { do } & \text { seu } \\
\text { departamento } & \text { a } \\
\text { finalidade e } & \text { as } \\
\text { atividades } & \\
\text { realizadas } & \text { pelos } \\
\text { outros dois? } & \end{array}$ & Sim. & Sim. & Sim. & Sim. \\
\hline $\begin{array}{l}\text { Questão } 7 \\
\text { Qual a finalidade } \\
\text { do material } \\
\text { processado } \\
\text { informacionalmente } \\
\text { e que relação } \\
\text { mantém com o } \\
\text { público interno e } \\
\text { externo? }\end{array}$ & $\begin{array}{l}\text { A finalidade é a } \\
\text { disponibilização } \\
\text { do material para } \\
\text { professores, } \\
\text { pesquisadores e } \\
\text { estudantes. Os } \\
\text { usuários } \\
\text { internos são os } \\
\text { professores e } \\
\text { alunos da } \\
\text { unidade, } \\
\text { enquanto os } \\
\text { usuários } \\
\text { externos } \\
\text { consistem em } \\
\text { pesquisadores } \\
\text { de outras } \\
\text { unidades. }\end{array}$ & $\begin{array}{l}\text { Pesquisa e } \\
\text { preservação } \\
\text { da memória } \\
\text { institucional. }\end{array}$ & $\begin{array}{l}\text { Material } \\
\text { trabalhado para } \\
\text { disponibilização } \\
\text { no sistema. } \\
\text { lgualmente } \\
\text { acessado por } \\
\text { usuário interno } \\
\text { e ou externo. }\end{array}$ & $\begin{array}{l}\text { A Biblioteca X é } \\
\text { uma biblioteca } \\
\text { pública e o seu } \\
\text { acervo destina-se } \\
\text { fundamentalmente } \\
\text { ao atendimento } \\
\text { das necessidades } \\
\text { de leitura e } \\
\text { informação para o } \\
\text { cidadão, sem } \\
\text { perder de vista } \\
\text { também o caráter } \\
\text { metropolitano da } \\
\text { instituição, assim } \\
\text { como, } \\
\text { atendimento das } \\
\text { necessidades } \\
\text { informacionais e } \\
\text { culturais dos } \\
\text { profissionais que } \\
\text { atuam. } \\
\text { importante } \\
\text { destacar }\end{array}$ \\
\hline
\end{tabular}

Inf. Inf., Londrina, v. 23, n. 01, p. $109-131$, jan./abr. 2018. http://www.uel.br/revistas/informacao/ 


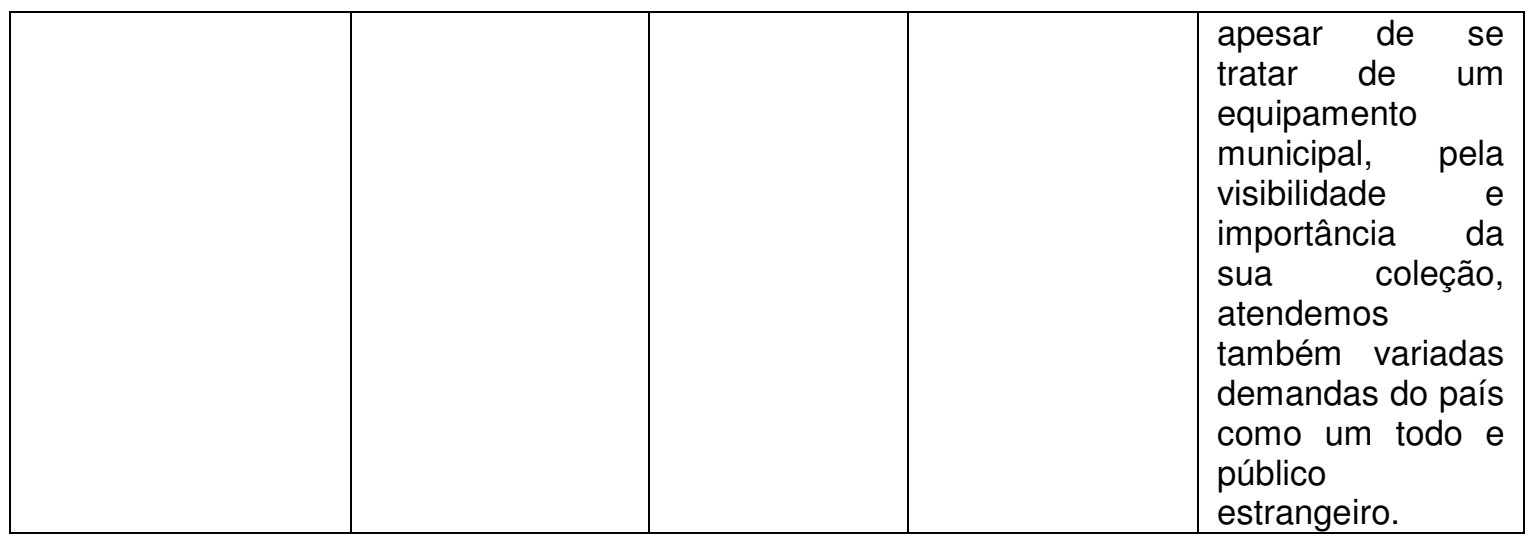

Fonte: Dados da pesquisa

Análise - Questões 1 e 2

Observa-se que existe tratamento temático e descritivo dos documentos de arte, porém cada instituição opera de um modo, sendo que a forma e o conteúdo nem sempre são, "ambos", contemplados, já que cada local possui acervos e objetivos diferenciados. Tais constatações são justificadas pelas próprias respostas: "representação pela indexação padrão (vocabulário controlado); tratamento técnico descritivo, para posterior digitação na planilha MARC; análise conceitual e temática do material a partir de uma leitura técnica". Nota-se, em alguns casos, que a representação descritiva e temática são tratadas como sinônimos, sem preocupação com a distinção de ambas e a operação de seus processos. Tal fato é preocupante, visto que trabalha-se diretamente com a disponibilização da informação que será transmitida ao público. Neste sentido, pode-se afirmar que de acordo com Maimone, Silveira e Tálamo (2011, p.28)

[...] a representação da informação pode ser subdividida em representação descritiva e representação temática. A primeira representa as características específicas do documento, denominada descrição bibliográfica, que permite a individualização do documento. Ela também define e padroniza os pontos de acesso, responsáveis pela busca e recuperação da informação, assim como pela reunião de documentos semelhantes, por exemplo, todas as obras de um determinado autor ou de uma série específica. A segunda detém-se na representação dos assuntos dos documentos a fim de aproximá-los, tornando mais fácil a recuperação de materiais relevantes que dizem respeito a temas semelhantes. Neste contexto, são elaboradas as linguagens documentárias, instrumentos de controle vocabular a fim de tornar possível a "conversação" entre documentos e usuários. 
Tanto a representação descritiva quanto a temática são importantes e necessárias para a fidedigna representação da informação e seu posterior acesso, porém, distingui-las é essencial para os profissionais que as operam, principalmente no âmbito dos documentos artísticos, que são, em muitos casos, complexos, específicos e cheios de detalhes.

Cabe ressaltar que as informações descritivas como nome do autor/pintor, título da obra, dimensões etc. são mais suscetíveis de tratamento e inserção na base de dados por possuírem normas já amplamente utilizadas e pela própria natureza da informação que carregam.

\section{Análise - Questão 3}

Observa-se que as especificidades "temáticas" das Artes não são contempladas de forma satisfatória nas instituições respondentes, pois os instrumentos utilizados resumem-se à normas de catalogação e mapeamentos de publicações de artistas, e/ou itinerários das obras. No campo das Artes, um assunto, por exemplo, pode envolver uma série de variáveis que vão desde a definição do conceito "assunto" até a subjetividade inerente do indexador ao inserir informações no sistema, fato, porém, que não justifica a ausência de instrumentos específicos para tal finalidade.

\section{Análise - Questões 4 e 5}

Três das quatro instituições dizem utilizar sistemas de integração de acervos, fato que demonstra preocupação quanto aos materiais existentes nos museus e os processos para tratamento conjunto. Neste sentido, tais atividades/trabalhos integrados podem ser observados com a formação de grupos de trabalhos temáticos, visitas monitoradas, palestras e eventos coletivos.

\section{Análise - Questão 6}

As quatro instituições afirmaram ser de conhecimento do seu departamento a finalidade $\mathrm{e}$ as atividades realizadas pelos outros dois. $\mathrm{O}$ aumento significativo de encontros multi e interdisciplinares têm permitindo que 
profissionais das três áreas (museu, arquivo e biblioteca) trabalhem conjuntamente, traçando, talvez, o início da jornada integrativa e cooperativa.

\section{Análise - Questão 7}

Quanto à finalidade do material processado informacionalmente, as respostas foram bastante diversas. Enfatiza-se que os sistemas de recuperação de informação são os veículos que tornam possível o acesso ao material, sendo que é urgente a inserção destes sistemas na rede de cooperação internacional para que as instituições possam permutar informações documentárias, documentos e experiências.

De modo geral observou-se que muito embora existam diferenças entre os objetivos dos museus, existem iniciativas (ainda em estágios iniciais) de integração tanto dos acervos quanto dos profissionais envolvidos com o trato informacional.

\section{CONCLUSÕES}

Os objetos de museu, documentos de arquivo, e materiais de biblioteca devem ser trabalhados como fontes de informação artística, de modo que tragam resultados de buscas integradas a fim de não apenas satisfazer as necessidades dos usuários, mas também despertar para possibilidades de conhecimento de novos conceitos, termos e possibilidades de pesquisas futuras.

Neste sentido, o tratamento documentário deve estar pautado em normas que orientem seus procedimentos e também em pesquisas que investiguem tendências de dispositivos midiáticos e linguísticos utilizados pela sociedade (público) que busca este tipo de informação.

Há que se enfatizar que a linguagem verbal é a única capaz de interpenetrar aos outros tipos de linguagens (CINTRA et al, 2002) - visual, oral, auditiva, cinematográfica, além de possibilitar a representação dos documentos de diversas naturezas. Fica evidente, portanto, a importância do uso de vocabulários controlados para a indexação dos materiais, assim como sistemas 
de classificação para sua organização física. Normas e padrões que regem a descrição dos documentos são essenciais para garantir a funcionalidade do acesso/recuperação da informação.

Apesar da evidente importância destas ferramentas elas se tornam pouco eficazes se usadas de modo segmentado pelos departamentos dos museus, bem como os sistemas de recuperação de informação que se mostram, neste caso, menos eficientes.

Por fim, considera-se fundamental o trabalho integrado de representação de documentos artísticos sob o aspecto "informativo", uma vez que agregam valor ao conteúdo das obras, pois beneficia a curadoria do museu na organização de exposições, a biblioteca na representação dos materiais, o arquivo pela possibilidade de complementação das pesquisas (com documentos relevantes), e o público pela percepção de complementaridade das obras.

\section{Agradecimentos}

À Fundação de Amparo à Pesquisa do Estado de São Paulo (FAPESP) - processo no 2014/06697-6.

\section{REFERÊNCIAS}

AMERICAN NATIONAL STANDARDS ORGANIZATION - ANSI. ANSI/NISO Z 39.19: 2005: guidelines for the construction, format, and management of monolingual controlled vocabularies. Bethesda: NISO Press, 2005. $176 \mathrm{p}$.

CINTRA, A. M. M. et al. Para entender as linguagens documentárias. 2. ed. rev. e ampl. São Paulo: Polis, 2002. 96 p.

CLASSIFICAÇÃO DECIMAL DE DEWEY. 23. ed. 2011. Disponível em: $<$ http://dewey.org/webdewey/login/login.html>. Acesso em: 23 abr. 2016.

COELHO, T. Dicionário Crítico de Política Cultural: cultura e imaginário. São Paulo: lluminuras, 1997. 
COMITÊ INTERNACIONAL DE DOCUMENTAÇÃO (CIDOC) / CONSELHO INTERNACIONAL DE MUSEUS (ICOM). Declaração de Princípios de Documentação em Museus e Diretrizes Internacionais de Informação sobre Objetos de Museus: categorias de informação do CIDOC. São Paulo: Secretaria de Estado de Cultura de São Paulo; Associação de Amigos do Museu do Café; Pinacoteca do Estado de São Paulo, 2014.

CUNHA, M. B. da; CAVALCANTI, C. R. de O. Dicionário de Biblioteconomia e Arquivologia. Brasília, DF: Briquet de Lemos/Livros, 2008.

DESVALLÉES, A.; MAIRESSE, F. (Ed.) Conceitos-chave de museologia. São Paulo: Comitê Brasileiro do Conselho Internacional de Museus: Pinacoteca do Estado de São Paulo: Secretaria do Estado da Cultura, 2013. 100 p.

FARIA, M. I.; PERICÃO, M. DA G. Dicionário do livro: da escrita ao livro eletrônico. São Paulo: EDUSP, 2008.

GARCíA CANO, J. M. La documentación en el museo arqueológico de Murcia. Anales de documentación, n. 2, p. $159-168.1999$.

HARPRING, P. Introduction to controlled vocabularies: terminology for art, architecture and other cultural Works. Los Angeles, California: Getty Research Institute, 2010. 244 p.

INSTITUTO NACIONAL DE ESTATÍSTICA DE PORTUGAL. Sistema Integrado de Metainformação. Disponível em: $<$ http://metaweb.ine.pt/sim/OPERACOES/DOCMET PDF/DOCMET PDF 653 1.pdf>. Acesso em: 25 jan. 2016.

INTERNATIONAL STANDARD ORGANIZATION. ISO 25964: thesauri and interoperability with other vocabularies. Part 1: Thesauri for information retrieval. Geneve: International Standard Organization, 2011.

INTERNATIONAL STANDARD ORGANIZATION. ISO 25964: thesauri and interoperability with other vocabularies. Part 2: Interoperability with other vocabularies. Geneve: International Standard Organization, 2012.

MAIMONE, G. D.; SILVEIRA, N. C.; TÁLAMO, M. F. G. M. Reflexões acerca das relações entre representação temática e descritiva. Inf. \& Soc.: Est., João Pessoa, v. 21, n. 1, p. 27-35, jan./abr. 2011.

PAES, M. L. Arquivo: teoria e prática. 3. ed. rev. e ampl. Rio de Janeiro: Editora FGV, 2004.

SANTOS, G. C.; RIBEIRO, C. M. Acrônimos, siglas e termos técnicos: arquivística, biblioteconomia, documentação, informática. Campinas, SP: Editora Átomo, 2003. 
SMIT, J. W. Arquivologia, Biblioteconomia e Museologia: o que agrega estas atividades profissionais e 0 que as separa? Revista Brasileira de Biblioteconomia e Documentação, v. 1, n. 2, p. 27 - 36. 1999-2000.

SPECTRUM 4.0: padrão para gestão de coleções de museus do Reino Unido. São Paulo: Secretaria de Estado de Cultura de São Paulo; Associação de Amigos do Museu do Café; Pinacoteca do Estado de São Paulo, 2014.

UDC CONSORTIUM - Classificação Decimal Universal. 3. ed. Lisboa, PT : Biblioteca Nacional, 2005.

\title{
INFORMATION REPRESENTATION OF ARTISTICS DOCUMENTS IN MUSEOLOGICAL ENVIRONMENT: AN EXPLORATORY ANALYSIS FROM THE VIEW POINT OF DEPARTAMENTAL INTEGRATION
}

\begin{abstract}
Introduction: It analyzes the integration of the museum, archive and library departments in a museum environment, with respect to the informational representation of the objects / artistic documents, being considered all materials referring to the arts, regardless of their support. Objectives: Identify the integration of professionals and collections of museum departments in relation to documentary treatment of different types of materials; to contextualize uses and ambiences of these documents, seeking to delimit boundaries of documentary application; and, compare documentary languages and related tools already existent in the area of arts.

Methodology: Studies and bibliographical analyzes on the subject in question, having as apllied part sending and return of questionnaires to art institutions in the city of São Paulo. Results: Although there are differences between the museums, this research revealed the existence of initiatives to integrate both the collections and the professionals involved in information processing. Conclusions: The integrated work of representation of artistic documents under the "informative" aspect is fundamental, since they add value to the content of the works.
\end{abstract}

Descriptors: Information representation. Artistics documents. Museums. Archives. Libraries. 


\title{
REPRESENTACIÓN INFORMACIONAL DE DOCUMENTOS ARTÍSTICOS EN AMBIENTE MUSEOLÓGICO: UN ANÁLISIS EXPLORATORIO DESDE EL PUNTO DE VISTA DE LA INTEGRACIÓN DEPARTAMENTAL
}

\begin{abstract}
Resumen
Introduction: Analiza la integración de los departamentos museo, archivo y biblioteca en ambiente museológico, en lo que se refiere a la representación informacional de los objetos / documentos artísticos, siendo que se consideraron todos los materiales referentes a las artes, independientemente de su soporte. Objetivos: Identificar la integración de los profesionales y de los acervos de los departamentos de museos en relación con el tratamiento documental de los diferentes tipos de materiales; Contextualizar usos y ambientes de estos documentos buscando delimitar fronteras de aplicación documental; Y comparar los lenguajes documentales y herramientas afines ya existentes en el área de artes. Metodología: Se realizaron encuestas y análisis bibliográficos sobre el tema en cuestión, teniendo como parte aplicada el envío y retorno de cuestionarios a las instituciones de arte de la ciudad de São Paulo. Resultados: Aunque existen diferencias entre los museos, esta investigación reveló la existencia de iniciativas de integración tanto de los acervos y de los profesionales involucrados con el trato informativo. Conclusiones: Es fundamental el trabajo integrado de representación de documentos artísticos bajo el aspecto "informativo", ya que agregan valor al contenido de las obras.
\end{abstract}

Descriptores: Representación del información. Documentos artísticos. Museos. Archivos. Bibliotecas. 